\title{
Fetal and maternal outcomes among pregnant women with placental abruption associated with disseminated intravascular coagulation attending a rural tertiary care centre
}

\author{
Sudha Mallidi, Munikrishna M.* \\ Department of Gynecology, Sri Devaraj URS Academy of Higher Education and Research, Bangalore, Karnataka, India
}

Received: 06 November 2021

Accepted: 26 November 2021

\section{*Correspondence:}

Dr. Munikrishna M.,

E-mail: drmunikrishna_m@rediffmail.com

Copyright: ( $)$ the author(s), publisher and licensee Medip Academy. This is an open-access article distributed under the terms of the Creative Commons Attribution Non-Commercial License, which permits unrestricted non-commercial use, distribution, and reproduction in any medium, provided the original work is properly cited.

\section{ABSTRACT}

Background: Placental abruption is the separation of the placenta from the uterine wall before the delivery of the fetus, and its frequency varies between 0.4 and $1 \%$. The objective of this study was to determine risk factors and maternal and fetal complications in cases of abruptio placentae.

Methods: A record-based study was conducted in the Obstetrics and Gynaecology department at a rural tertiary care centre between January 2015 and December 2019. All 72 pregnant women admitted with suspicion of placental abruption at 28 weeks of gestation and beyond were included in the study. All data were retrieved from the maternity register, patient files. The maternal outcome was assessed by mode of delivery, need for blood transfusion, parity, and any complications. Neonatal outcome was assessed by neonatal intensive care unit admission, still and live births. Data collected was entered and analysed by using coGuide software.

Results: A total of 72 subjects were included in the final analysis. Most 58 (81\%) of them were 21-30 years old. Fortythree patients $(59.72 \%)$ were diagnosed to be preeclamptic. Forty-three $(59.72 \%)$ of them had a vaginal delivery. Out of 72, 66 (91.67\%) patients did not have any maternal complications. Most 41 (56.94\%) births were stillbirths, and only $7(9.72 \%)$ newborns required intensive care unit (ICU) admission.

Conclusions: Placental abruption is one of the major threats to the well-being of pregnant women, with an alarmingly high rate of 41 (56.94\%) stillbirths.

Keywords: Abruption placentae, Disseminated intravascular coagulation, Postpartum hemorrhage, Perinatal mortality, Maternal mortality

\section{INTRODUCTION}

Placental abruption (PA) is defined as the complete or partial separation of a normally implanted placenta before delivery occurs in $0.4-1.0 \%$ of all pregnancies. It is a serious multifactorial obstetric complication, and its etiopathogenetic mechanism is not yet entirely understood. ${ }^{1}$ In cases of PA occurring concomitantly with disseminated intravascular coagulation (DIC), emergency caesarean delivery is performed due to non-reassuring fetal status, cerebral palsy, critical bleeding, uncontrollable bleeding requiring hysterectomy, multiorgan failure, and maternal and fetal death. Thus, placental abruption requires timely perinatal management to avoid further consequences. ${ }^{2}$

Hypertensive during pregnancy, chorioamnionitis, advanced maternal age, smoking, cocaine use, and undernutrition are a few risk factors for placental abruption. A 5.8\% recurrence rate of placental abruption is reported in subsequent pregnancies. ${ }^{3}$ Vaginal delivery after placental abruption is recommended for quick recovery and discharge from hospital times and the next successful pregnancy and delivery. Immediate rupture of 
the membranes is the key to successful labor and delivery. ${ }^{4}$ The prevalence of placental abruption is 3-10 per 1000 deliveries. However, the prevalence in developed countries in the last 30 years has shown a decreasing trend..$^{5}$ Placental abruption can occur suddenly without any premonitory signs and increases the risk of stillbirth to $9.6 \%$ and $17.6 \%$ during the antepartum and intrapartum periods, respectively. ${ }^{2}$ The risk of neonatal mortality is reportedly as high as $11.9 \% .3$ In addition, placental separation allows tissue factors released from the placental tissue to enter the maternal circulation and promote thrombin generation and coagulation, which can cause DIC that can progress to massive post-partum hemorrhage (PPH), renal failure, and a life-threatening situation for the mother. ${ }^{6}$

Placental abruption is common in the third trimester of pregnancy. However, it might occur in the first and second trimesters too. The incidence of placental abruption is $1 \%$ in singleton pregnancies which is almost doubled in twin gestations. Clinical diagnosis of placental abruption is based on signs and symptoms like vaginal bleeding, mild to moderate abdominal pain, and uterine contractions. Abruption is confirmed after placental delivery by evaluating the retro-placental clots or depression in the maternal surface of the placenta. The classic clinical hallmark is vaginal bleeding, which may be present in up to $80 \%$ to $90 \%$ of cases. ${ }^{7}$ Ultrasonography criteria for diagnosis of placental abruption include pre placental collection under chorionic plate, jell-like movement of a chorionic plate with fetal activity, retro placental collection, marginal subchorionic hematoma, increased placental thickness $>5 \mathrm{~cm}$, and intra-amniotic hematoma. ${ }^{8}$

A previous study by Saquib et al in Dubai hospital showed PA as $0.61 \%$ in a total of 15,079 deliveries. ${ }^{9}$ The antenatal risk factors associated with abruption were diabetes $(26 \%)$, chronic hypertension (2.2\%), preeclampsia (19.5\%), previous caesarean section $(26 \%)$, and multiple pregnancies $(9.8 \%)$. The delivery mode was through caesarean section in $78 \%$ of abruption cases. $33 \%$ had a postpartum hemorrhage, and $20 \%$ had received blood products. $51 \%$ of the patients had a preterm delivery, $47 \%$ of the babies had a birth weight of less than $2.5 \mathrm{~kg}, 8$ cases died of intrauterine fetal death, and one neonatal death. Another study by $\mathrm{Su} \mathrm{J}$ et al. ${ }^{10}$ in China showed the volumes of antepartum, intrapartum, and $\mathrm{PPH}$, and the rates of uteroplacental apoplexy, uterine compression sutures, and vascular embolization significantly increased with increasing placental abruption severity. Fetal delivery data revealed that 1- and 5- min Apgar scores decreased substantially with increasing placental abruption severity.

Not many studies have been reported from developing countries, especially India, as abruption placenta is a lifethreatening complication of pregnancy and is associated with poor maternal and fetal outcomes if not managed properly. Therefore, the current study was aimed to determine obstetrical risk factors and the subsequent fetomaternal outcome among pregnant women attending a tertiary care institute with placental abruption.

\section{Aims and objectives}

Aim and objective of the study was to determine obstetrical risk factors and the subsequent fetomaternal outcome in placental abruption.

\section{METHODS}

\section{Study design}

The study was a retrospective observational study.

\section{Study setting}

The obstetrics and gynecology department at a rural tertiary care centre was the study setting.

\section{Source population}

It included pregnant women attending the obstetrics and gynecology department of a rural tertiary care centre.

\section{Study population}

It included pregnant women with abruption placenta and DIC attending the obstetrics and gynecology department of tertiary care institute.

\section{Study period}

In the study, data was collected between January 2015 and December 2019.

\section{Sample size}

All 72 pregnant women with abruption placenta and DIC were considered as sample size.

\section{Sampling technique}

The sample was selected using the non-probability sampling technique for the feasibility of the study.

\section{Sample size calculation}

$10 \%$ estimate based on preeclamptic condition in placental abruption $(75 \%)$ according to Mishra et al. ${ }^{11}$ With an absolute error of $10 \%$, the estimated sample size is 72 cases.

\section{Ethical and informed consent}

The study was approved by honourable committee members of the institutional review board. After explaining the study objectives and before the start of the 
study, informed written consent was obtained from all participants. Patients' information was kept confidential.

\section{Inclusion criteria}

After 28 weeks of gestation, women with singleton pregnancy, severe preeclampsia, antepartum eclampsia, and imminent eclampsia were included.

\section{Exclusion criteria}

Pregnant women with diabetes or gestational diabetes, hemoglobinopathies, nephropathy, acute and chronic renal failure, glomerulopathy, hepatic dysfunction, gout, hypothyroidism or hyperthyroidism, fetal and placental malformations, and multiple pregnancies were excluded.

\section{Data collection}

Data of patients admitted with suspicion of placental abruption at 28 weeks of gestation and beyond was considered. All data were retrieved from the maternity register, patient files. The maternal outcome was assessed by mode of delivery, PPH, need for blood transfusion, DIC, intensive care unit (ICU) admission, or multiorgan failure. Neonatal outcome was assessed by preterm birth, low Apgar score, neonatal intensive care unit admission, and perinatal death.

\section{Operational definitions}

Placental abruption was defined as the partial or complete separation of the placenta before the delivery of the fetus. This diagnosis was made by the senior attending obstetrician based on the clinical presentation, ultrasound findings, cardiotocography (CTG) monitoring, and laboratory findings. The extent of placental abruption was based on the gross clinical examination of the placenta by the attending obstetricians (at least two) at the time of delivery. PA can be classified as: mild abruption, <20\%; moderate abruption, 20-49\%; and severe abruption, $>50 \%$.

The diagnosis of PA was confirmed when patients noticed symptoms such as vaginal bleeding, mild to moderate abdominal pain, and uterine contractions. ${ }^{12}$

\section{Study variables}

Maternal and perinatal outcomes in terms of complications, risk factors, blood transfusion, stillbirth, and ICU admission were considered as primary outcome variables. Age, mode of delivery, and parity were considered as other explanatory variables.

\section{Statistical methods}

Descriptive statistics were used to explain the findings of data following the study's objectives. Frequencies and proportions were used for representing categorical data and mean and standard deviation for continuous data. Data collected was entered and analysed by using coGuide software. ${ }^{13}$

\section{RESULTS}

A total of 72 subjects were included for the final analysis.

The maximum number of cases 29 (40.28\%) of abruption placenta were between 21 to 25 years, followed by 29 $(40.28 \%)$ in the 26 to 30 years age group. The least incidence was seen among the age group 31 to 35 years in $5(6.94 \%)$ cases, and $3(4.17)$ cases were 36 years and above (Table 1).

Table 1: Summary of age group $(\mathrm{N}=72)$.

\begin{tabular}{|ll|}
\hline Age (in years) & Summary $(\%)$ \\
\hline Upto 20 & $6(8.33)$ \\
\hline $\mathbf{2 1}$ to 25 & $29(40.28)$ \\
\hline $\mathbf{2 6}$ to 30 & $29(40.28)$ \\
\hline $\mathbf{3 1}$ to 35 & $5(6.94)$ \\
\hline $\mathbf{3 6}$ and above & $3(4.17)$ \\
\hline
\end{tabular}

In most cases, $51(70.83 \%)$ were multigravida, and 21 (29.17\%) were primigravida. Out of 72,43 (59.72\%) patients with pre-eclampsia had abruption placenta, 6 $(8.33 \%)$ patients had complications during delivery, 23 (31.94\%) had packed red blood cells (PRBC) required blood transfusion, 15 (20.83\%) had PRBC and fresh frozen plasma (FFP) and $12(16.67 \%)$ had PRBC and FFP and platelet (PLT). The majority, 43 (59.72\%), delivered vaginally, and $29(40.28 \%)$ patients underwent $\mathrm{C}$ section (Table 2).

Table 2: Summary of maternal outcomes $(\mathrm{N}=72)$.

\begin{tabular}{|ll|}
\hline Parameter & Summary (\%) \\
\hline Parity & $21(29.17)$ \\
\hline Primi & $51(70.83)$ \\
\hline Multi & \\
\hline Normal BP & $29(40.28)$ \\
\hline Pre eclampsia & $43(59.72)$ \\
\hline Complications & $6(8.33)$ \\
\hline Yes & $66(91.67)$ \\
\hline No & \\
\hline Blood transfusion & $23(31.94)$ \\
\hline PRBC & $15(20.83)$ \\
\hline PRBC+FFP & $12(16.67)$ \\
\hline PRBC +FFP+ PLT & $22(30.56)$ \\
\hline Not required & \\
\hline Mode of delivery & $43(59.72)$ \\
\hline Vaginal & $29(40.28)$ \\
\hline C section & \\
\hline
\end{tabular}

Seven $(9.72 \%)$ babies were admitted to ICU, 41(56.94\%) were stillborn, and 31 (43.06\%) were live birth. (Table 3). 
Table 3: Summary of fetal outcomes $(\mathrm{N}=72)$.

\begin{tabular}{|ll|}
\hline Parameter & Summary $(\%)$ \\
\hline ICU admission & \\
\hline Yes & $7(9.72)$ \\
\hline No & $65(90.28)$ \\
\hline Fetal outcome & \\
\hline Still birth & $41(56.94)$ \\
\hline Live & $31(43.06)$ \\
\hline
\end{tabular}

\section{DISCUSSION}

The present study sought maternal and perinatal outcomes among pregnant women with abruption placenta attending a tertiary care institute. The study's main findings showed that 21-30 years was the most common age of placental abruption. Nearly half of the study population, 29 $(40.28 \%)$, was diagnosed with preeclampsia. Only 6 (8.33\%) patients had maternal complications. Most 41 (56.94\%) births were stillbirths, and only 7 (9.72\%) newborns required ICU admission.

In the present study, the maximum number of $58(81 \%)$ abruption placenta cases was between 21 to 30 years. The finding was in compassion to a study by Kapadiya et al where 21-30 years age group had maximum cases. ${ }^{14}$ The result was in contrast to a retrospective cohort analysis by Ananth et al in the United States of America (USA), where the maternal age 40 years or older was associated with increased rates of abruption. ${ }^{15}$ In the current study, 43 $(59.72 \%)$ patients out of 72 were diagnosed with preeclampsia. This finding contrasts to a retrospective study by Atkinson et al in New-jersey, where only 8 $(17.8 \%)$ out of 61 patients had preeclampsia. ${ }^{16}$ In Japan, another case control study by Hasegawa et al, 16 concluded that placental abruptions were associated with severe preeclampsia during the antenatal period.

In the present study, $43(59.72 \%)$ delivered vaginally, and $29(40.28 \%)$ patients underwent a $\mathrm{C}$ section. This finding contradicted a study by Boisramé et al in France, where the CS rate was $90.3 \%$, with $51.8 \%$ being performed under general anesthesia. ${ }^{17}$ In most cases, 51 (70.83\%) were multigravida in the present study, and $21(29.17 \%)$ were primigravida. The finding is in comparison to a study by Igwegbe et al where high parity, advanced maternal age, low socioeconomic status, cigarette smoking, abdominal trauma, alcohol use, crack cocaine use in pregnancy, maternal hypertension, polyhydramnios, multiple pregnancies, thrombophilia's, and prior history of abruption have all been identified as risk factors. ${ }^{18}$

In the present study, maternal outcomes were less due to blood component transfusion. Most 41 (56.94\%) births were stillbirths, and $31(43.06 \%)$ were live births. These findings were comparable to an observational study by Wahane et al in India, out of 140 women, 42 were live babies while 39 were stillborn babies. ${ }^{19}$ Overall, the maternal outcome was also good due to proper obstetrics care, a wide range of antibiotics, and blood component transfusion. Only $6(8.33 \%)$ patients had maternal complications in the present study.

The most common and serious complication factor of PPH is placental abruption. Timely management of placental abruption is of utmost importance as It is a risk factor for both mother and infant's life if went unrecognized or uncontrolled. The worldwide incidence of placenta abruption is reportedly $1 \%$. However, it has shown a declining incidence. This decline can be attributed to rapid economic development, improved pregnancy care, enhanced public health care awareness, and the increasing number of pregnancies receiving regular examinations at hospitals. However, some mild cases of placental abruption are misdiagnosed or ignored. Thus, the potential risk factors for preterm placenta require investigation. ${ }^{20}$

\section{Strength}

The findings of the present study will improve the management of pregnant women with placental abruption. The study was clinically relevant, and information can counsel patients regarding the adverse effects of placental abruptions.

\section{Limitations}

The main limitation is the study design which is retrospective in nature. Second, the sample size was small as it was a single-center study. The data on a few variables like maternal education, gestational age, pregestational diabetes, gestational diabetes, chronic renal disease, asthma, and congenital cardiac disease, anemia, intrapartum fever, chorioamnionitis, weight gain during pregnancy was lacking, and hence the possibility of the associations being affected by unmeasured confounders remains as such.

\section{Future perspectives}

Further multicentric prospective longitudinal studies are recommended to provide external validity of these findings and a more precise evaluation of other unexplored variables.

\section{CONCLUSION}

The study concluded abruption placenta as a significant cause of neonatal and perinatal mortality. Diagnosing the severity of placental separation precisely is challenging. The incidence of abruption can be decreased by providing proper antenatal care, early diagnosis, availability of blood transfusion, strict surveillance, prompt action at the time of occurrence. Thus, future management strategies should focus on prevention, screening by providing awareness regarding the initial symptoms and the prognosis of PA to all pregnant thereby improving maternal and fetal outcomes. 


\section{ACKNOWLEDGMENTS}

Authors would like to acknowledge the technical support in data entry, analysis and manuscript editing by Evidencian Research Associates.

\section{Funding: No funding sources}

Conflict of interest: None declared

Ethical approval: The study was approved by the Institutional Ethics Committee

\section{REFERENCES}

1. Tikkanen M. Placental abruption: epidemiol- ogy, risk factors and consequences. Acta Obstet Gynecol Scand. 2011;90(2):140-9.

2. Takeda J, Takeda S. Management of disseminated intravascular coagulation associated with placental abruption and measures to improve outcomes. Obstet Gynecol Sci. 2019;62(5):299-306.

3. Ruiter L, Ravelli ACJ, de Graaf IM, Mol BWJ, Pajkrt E. Incidence and recurrence rate of placental abruption: a longitudinal linked national cohort study in the Netherlands. Am J Obstet Gynecol. 2015;213(4):573.

4. Imanaka S, Naruse K, Akasaka J, Shigemitsu A, Iwai K, Kobayashi H. Vaginal delivery after placental abruption and intrauterine fetal death, including failed cases. Int J Gynecol Obstet. 2014;126(2):180-1.

5. Ananth CV, Keyes KM, Hamilton A, Gissler M, Wu $\mathrm{C}$, Liu S, et al. An international con- trast of rates of placental abruption: An age-period-cohort anal- ysis. PLoS One. 2015;10:e0125246.

6. Wang L, Matsunaga S, Mikami Y, Takai Y, Terui K, Seki H. Pre-delivery fibrinogen predicts adverse maternal or neonatal outcomes in patients with placental abruption. J Obstet Gynaecol Res. 2016;42(7):796-802.

7. Shinde GR, Vaswani BP, Patange RP, Laddad MM, Bhosale RB. Diagnostic performance of Ultrasonography for detection of abruption and its clinical correlation and maternal and foetal outcome. J Clin Diagnostic Res. 2016;10(8):4-7.

8. Oyeless YAC. Placental abruption. J Am Obs Gynaecol. 2006;108(4):1005-16.

9. Saquib S, Hamza LK, AlSayed A, Saeed F, Abbas M. Prevalence and Its Feto-Maternal Outcome in Placental Abruption: A Retrospective Study for 5 Years from Dubai Hospital. Dubai Med J. 2020;3(1):26-31.

10. Su J, Yang Y, Cao Y, Yin Z. The predictive value of pre-delivery laboratory test results for the severity of placental abruption and pregnancy outcome. Placenta. 2021;103:220-5.

11. Mishra R, Misra AP. Abruptio placenta and its maternal and fetal outcome. Int J Reprod Contracept Obstet Gynecol. 2019;8(8):3323.

12. Onishi K, Tsuda H, Fuma K, Kuribayashi M, Tezuka A, Ando T, et al. The impact of the abruption severity and the onset-to-delivery time on the maternal and neonatal outcomes of placental abruption. J Matern Neonatal Med. 2020;33(22):3775-83.

13. BDSS Corp. coGuide Statistics software, Version 1.03, India. BDSS corp. 2020. Available at: https://www.coguide.in. Accessed on 19 October 2021.

14. Kapadiya LDB. Study of Maternal and Perinatal Outcome in 100 case of Abruptio Placentae. J Med Res Heal Sci. 2017;6(7):84-8.

15. Ananth CV, Lavery JA, Vintzileos AM, Skupski DW, Varner M, Saade G, et al. Severe placental abruption: Clinical definition and associations with maternal complications. Am J Obstet Gynecol. 2016;214(2):272.

16. Atkinson AL, Santolaya-Forgas J, Blitzer DN, Santolaya JL, Matta P, Canterino J, et al. Risk factors for perinatal mortality in patients admitted to the hospital with the diagnosis of placental abruption. J Matern Neonatal Med. 2015;28(5):594-7.

17. Boisramé T, Sananès N, Fritz G, Boudier E, Aissi G, Favre R, et al. Placental abruption: Risk factors, management and maternal-fetal prognosis. Cohort study over 10 years. Eur J Obstet Gynecol Reprod Biol. 2014;179:100-4.

18. Igwegbe AO, Eleje GU, Okpala BC. Management outcomes of abruptio placentae at Nnamdi Azikiwe University Teaching Hospital, Nnewi, Nigeria. Niger J Med. 2013;22(3):234-8.

19. Wahane DA, Zele DM, Patil DB. A study of maternal and fetal outcome in cases of abruptio placentae. Int $\mathrm{J}$ Clin Obstet Gynaecol. 2020;4(4):71-4.

20. Li Y, Tian Y, Liu N, Chen Y, Wu F. Analysis of 62 placental abruption cases: Risk factors and clinical outcomes. Taiwan J Obstet Gynecol. 2019;58(2):2236.

Cite this article as: Mallidi S, Munikrishna M. Fetal and maternal outcomes among pregnant women with placental abruption associated with disseminated intravascular coagulation attending a rural tertiary care centre. Int J Reprod Contracept Obstet Gynecol 2022;11:187-91. 